\title{
Severe alveolar bone loss and internal root resorption in linear $\lg A$ disease and eosinophilic granulomatosis with polyangiitis: A rare case report
}

\section{Nasilony ubytek kości wyrostka zębodołowego i wewnętrzna resorpcja korzeni zębów w przebiegu linijnej IgA dermatozy oraz eozynofilowej ziarniniakowatości z zapaleniem naczyń - opis rzadkiego przypadku}

\author{
Phisut Amnuaiphanit ${ }^{A-F}$, Sarinthon Pariyawathe ${ }^{A-F}$, Kobkan Thongprasom ${ }^{A-F}$ \\ Department of Oral Medicine, Faculty of Dentistry, Chulalongkorn University, Bangkok, Thailand \\ A - research concept and design; $B$ - collection and/or assembly of data; $C$ - data analysis and interpretation; \\ $D$ - writing the article; $E$ - critical revision of the article; $F$ - final approval of article
}

Address for correspondence

Kobkan Thongprasom

E-mail: kobkan.t@chula.ac.th

Funding sources

none declared

Conflict of interest

none declared

\section{Acknowledgements}

We express our sincere thanks to the physicians of the General Medicine Department, Faculty of Medicine, King Chulalongkorn Memorial Hospital, Ramathibodi Hospital and Phayathai Hospital, Bangkok, Thailand for providing the investigation, information, and treatment of this case. We thank dr. Kevin Tompkins for manuscript editing. We also thank dr. Warangkana Yanyongkasemsuk and the Oral Medicine Department staff for their assistance. Our thanks also go to dr. Pischa Pittayawat for the oral radiographic interpretation.

Received on March 10, 2017

Revised on May 08, 2017

Accepted on May 28, 2017

\begin{abstract}
Linear IgA disease $(L A D)$ is rare and there are only a few cases reported where its lesions were limited to the oral mucosa. Eosinophilic granulomatosis with polyangiitis (EGPA) is also a rare multisystemic disease. Therefore, the occurrence of $L A D$ and EGPA in the same patient is very rare.

Here we report the oral manifestations of a case of a 24-year-old female who first presented with idiopathic thrombocytopenic purpura (ITP) and was treated with dapsone, with LAD occurring later. Over the next 6 years, this patient developed hypothyroidism, asthma, eosinophilia, glaucoma, abnormal menstruation, arthritis, glomerulonephritis and respiratory tract involvement. Finally, EGPA was diagnosed by her physicians. This is the first case report of LAD and EGPA that radiographically showed the development of generalized severe alveolar bone loss and internal root resorption of the maxillary right second premolar between the first visit and a 2-year follow-up.
\end{abstract}

Key words: linear IgA disease, eosinophilic granulomatosis with polyangiitis, alveolar bone loss, internal root resorption,

Słowa kluczowe: linijna IgA dermatoza, ziarniniakowatość eozynofilowa z zapaleniem naczyń, ubytek kości wyrostka zębodołowego, wewnętrzna resorpcja korzeni

D0I

10.17219/dmp/74144

Copyright

() 2017 by Wroclaw Medical University

and Polish Dental Society

This is an article distributed under the terms of the

Creative Commons Attribution Non-Commercial License

(http://creativecommons.org/licenses/by-nc-nd/4.0/) 
Linear immunoglobulin A disease (LAD) is a rare subepithelial blistering autoimmune disorder characterized by linear deposits of IgA along the basement membrane zone. ${ }^{1,2}$ LAD predominantly affects the skin and mucous membranes; however, the occurrence of lesions limited to the oral mucosa is rare. ${ }^{3}$ Most LAD cases are idiopathic; however, certain drugs, infections, trauma, autoimmune disorders and malignancies can be potential inducers. ${ }^{3-6}$ Some authors have proposed that it may be precipitated by diclofenac, ${ }^{6}$ lithium carbonate, ${ }^{7}$ statins, ${ }^{8}$ piroxicam, ${ }^{9}$ acetaminophen, ${ }^{10}$ amiodarone, ${ }^{11}$ ampicillin/sulbactam, ${ }^{12}$ metronidazole, ${ }^{13}$ amoxicillin-clavulanic acid, ${ }^{14}$ interferon- $\alpha 2 \mathrm{a},{ }^{15}$ trimethoprim-sulfamethoxazole ${ }^{16}$ and vancomycin. ${ }^{17}$ LAD have shown oral manifestation such as desquamative gingivitis, persistence of ulceration and the management of the oral lesions are very difficult. ${ }^{18}$

Eosinophilic granulomatosis with polyangiitis (EGPA) is a rare multisystemic disorder that affects small-to-medium-sized vessels and is associated with severe asthma and eosinophilia. ${ }^{19}$ The pathogenesis of EGPA is still unknown but eosinophils are the most characteristic cells in this disease. Anti-neutrophil cytoplasmic antibody (ANCA) associated vasculitis of the small vessels, especially glomerulonephritis, is another feature of EGPA. ${ }^{20,21}$ Generalized severe alveolar bone loss in an LAD/EGPA case has never been reported.

\section{Case report}

A 24-year-old female patient was referred to the clinic of the Department of Oral Medicine in 2014 with complaints of a burning sensation and bullous eruption in the oral cavity during the past 2 years. She was initially diagnosed with idiopathic thrombocytopenic purpura (ITP) in 2010, and was treated with dapsone by her physicians. However, she developed a severe hypersensitivity reaction on the skin and subsequently received $60 \mathrm{mg} /$ day prednisolone. After treatment, the skin showed improvement. In 2011, she went to the dentist for orthodontic treatment and during treatment, bullous eruptions began in the oral cavity along with slight tooth mobility. The history of tooth mobility was unclear, however, it gradually developed during her orthodontic treatment. Despite this mobility, successful minor tooth movement was completed within that year. In 2014, a biopsy specimen taken from her lesion showed IgA deposited at the basement membrane and LAD was diagnosed by her physician. Because the lesions were limited to the oral mucosa, her physician referred her to our clinic for treatment.

At the patient's first visit in 2014, an extraoral examination showed generalized skin hypopigmentation and nail grooves. Intraoral examination showed blood filled bullae on the gingiva at the maxillary right second premolar and left lateral incisor, and petechial hemorrhage on the lingual gingiva of her mandibular anterior teeth and the dorsal

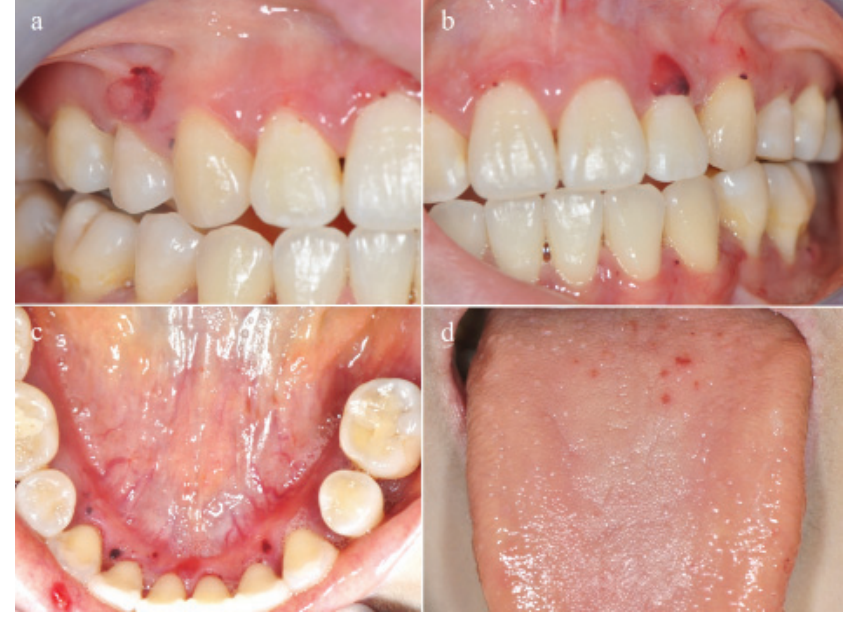

Fig. 1. (a) Blood filled bullous on gingiva of maxillary right second premolar, (b) left lateral incisor, and (c) petechial hemorrhage at the mandibular gingiva at the lingual aspect of the anterior teeth and (d) the dorsal surface of the tongue

surface of the tongue (Fig. 1a-d). We referred her to the Periodontology Department for treatment. Fluocinolone acetonide $0.1 \%$ with clotrimazole gel was prescribed to apply on the lesions and an oral hygiene check-up was performed. Her symptoms and bullae showed improvement. She did not attend follow-up visits and returned to our clinic in July 2016. At that time, the oral lesions were worse and we referred her to a dermatologist for further treatment.

Interestingly, during 2010-2016, she developed arthritis, glaucoma, abnormal menstruation, eosinophilia, hypothyroidism, asthma, respiratory tract involvement, and glomerulonephritis. Based on these findings, her physicians diagnosed her systemic disease as eosinophilic granulomatosis with polyangiitis (EGPA) and treated her with mycophenolate mofetil $500 \mathrm{mg} 1$ tablet b.i.d., tacrolimus $0.5 \mathrm{mg}$ 1 tablet o.d., prednisolone 1 tablet o.d., levothyroxine 0.1 mg 1 tablet o.d., enalapril 5 mg $1 / 2$ tablet o.d., simvastatin 10 mg 1 tablet h.s., and vitamin D (20,000 U) 1 tablet weekly.

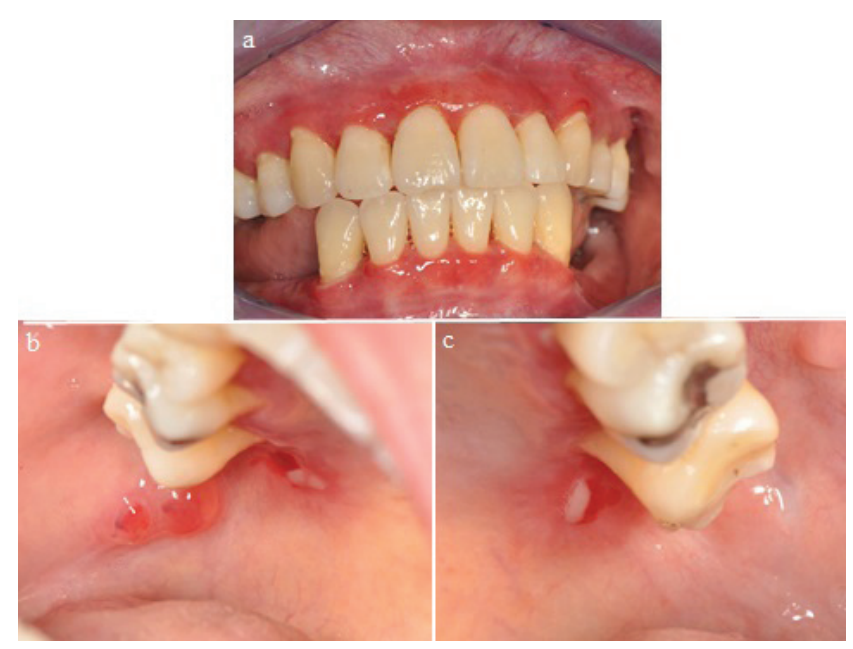

Fig. 2. (a) Generalized erythematous gingiva is seen and ( $b$ and c) blood filled bullae ( $5 \mathrm{~mm}$ and $3 \mathrm{~mm}$ ) on the right buccal mucosa with bullous rupture. Bullous rupture $(8 \times 3 \mathrm{~mm})$ was found on the right and the left hard palate area second molar 


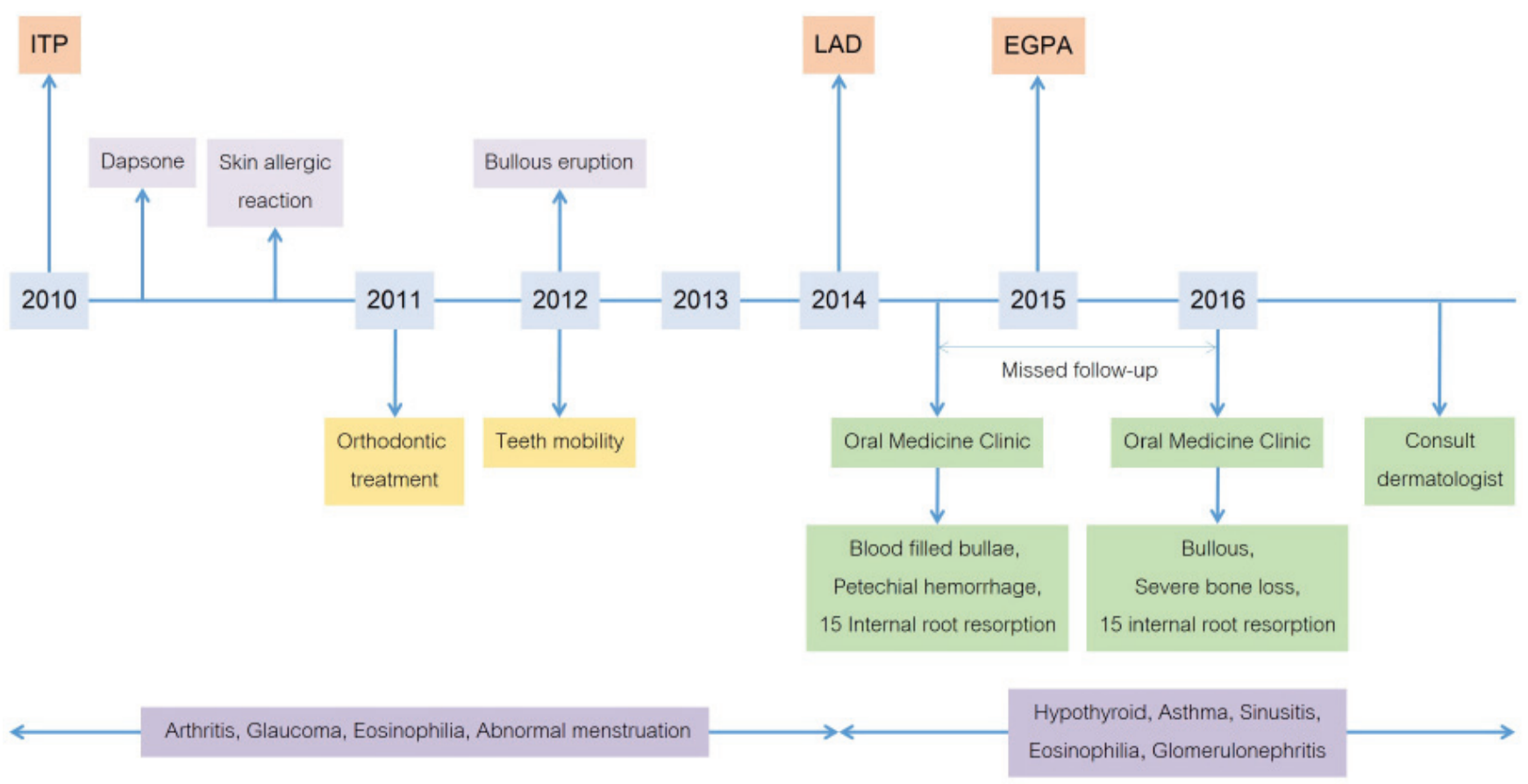

Fig. 3. Timeline of the occurrence of the oral lesions and developing diseases

In December 2016, she returned to our clinic with chief complaints of a burning sensation and bullous rupture in the oral cavity without skin lesions. Generalized erythematous gingiva and $5 \mathrm{~mm}$ and $3 \mathrm{~mm}$ blood filled bullae on the right buccal mucosa were observed. Ruptured $8 \times 3 \mathrm{~mm}$ bullae were found on the right and the left hard palate areas of the second molar (Fig. $2 \mathrm{a}-\mathrm{c})$. Triamcinolone acetonide $0.1 \%$ mouthwash was prescribed to treat the oral lesions, however, the lesions only showed slight improvement. The timeline of the occurrence of the oral lesions and developing diseases is shown in Fig. 3.

Oral radiographic findings showed internal root resorption of the maxillary right second premolar and generalized severe alveolar bone loss between the first visit in 2014 and the 2-year follow-up (Fig. 4-6). Although the internal root resorption size was similar to that observed at the first visit, the patient demonstrated generalized progressive bone loss since her initial visit. In addition, many teeth showed apical root resorption.

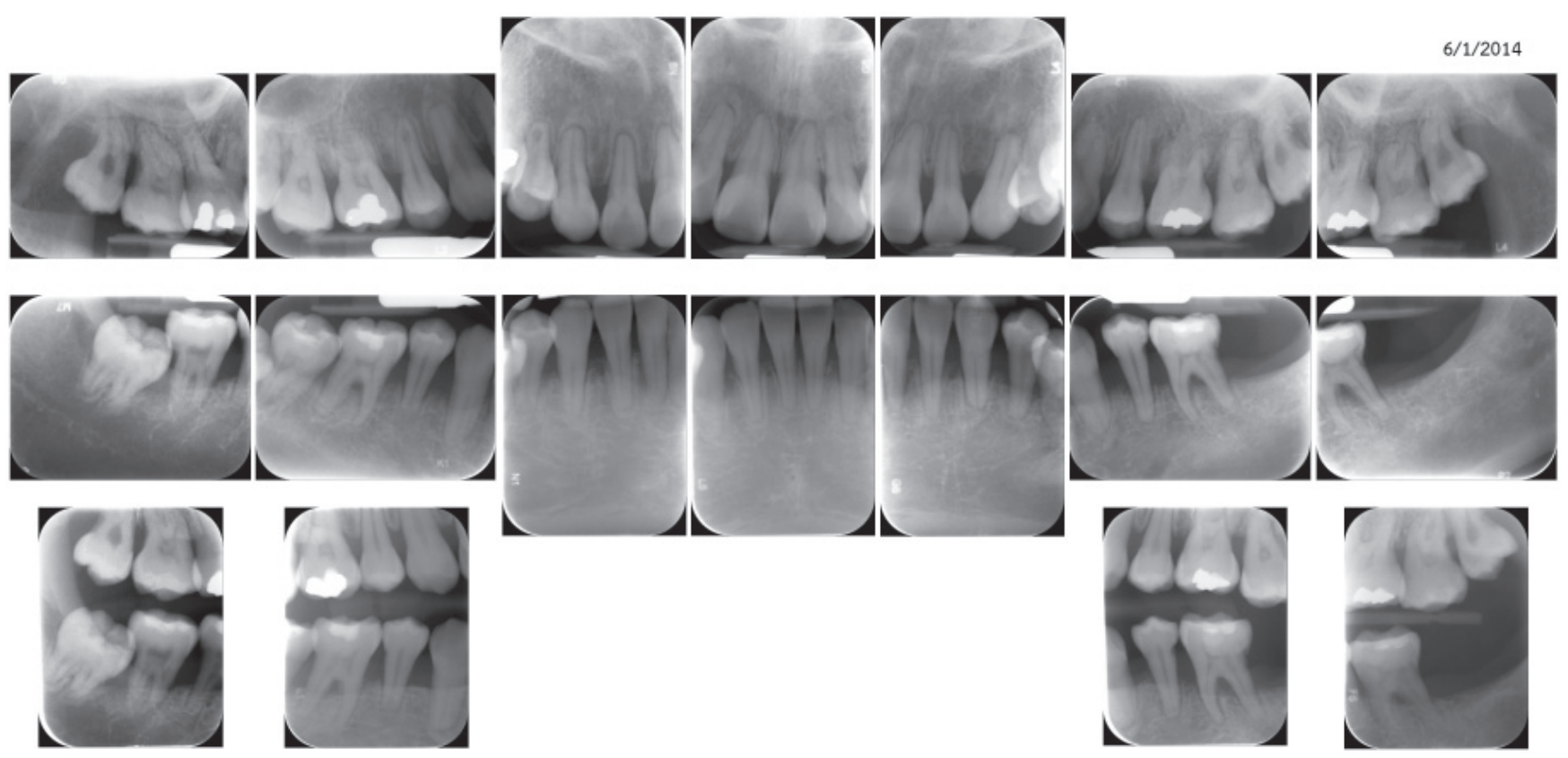

Fig. 4. Oral radiographic findings showing internal root resorption of the maxillary right second premolar and generalized severe bone loss at the first visit (January 2014) 


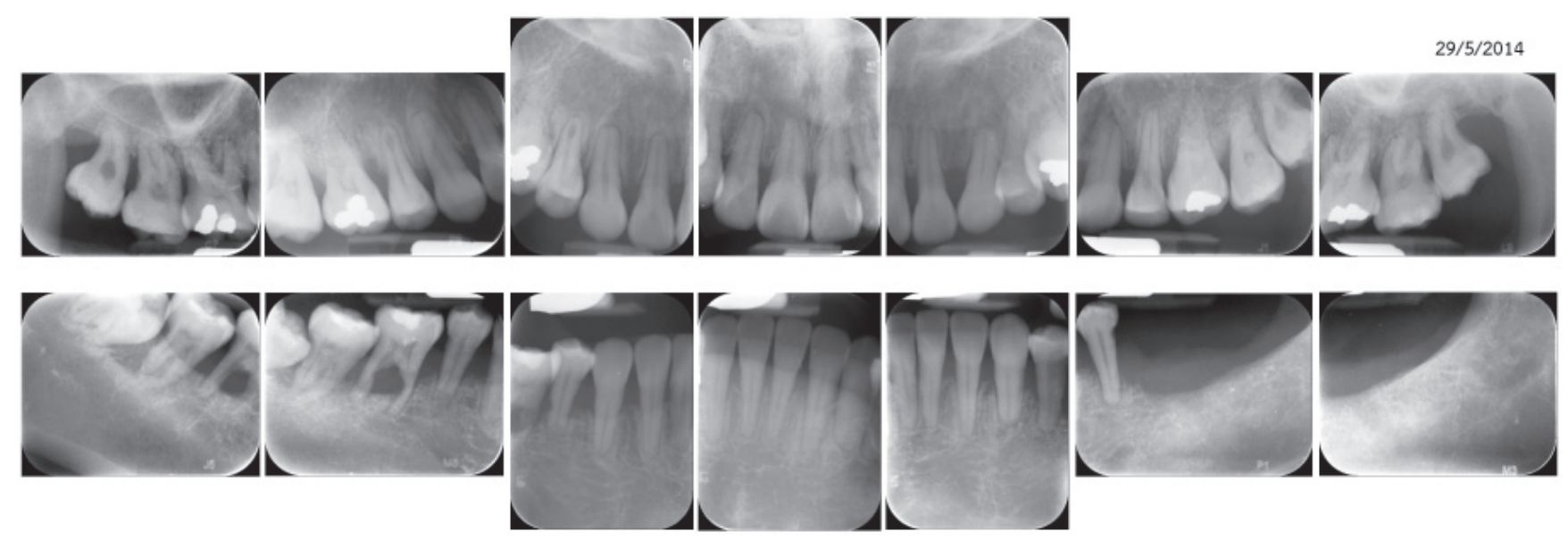

Fig. 5. May 2014, mandibular right first and second molars demonstrated bone destruction. The first molar was extracted. The size of the internal root resorption site on the maxillary right second premolar was unchanged

\section{Discussion}

Vesiculobullous lesions are common in the oral mucosa; however, LAD is a rare disease. The involvement of only the oral mucosa in LAD is rare and commonly presents as desquamative gingivitis. ${ }^{3,22,23}$ However, LAD treatment does not always control the progression of the disease. To our knowledge, this is the first case of LAD and EGPA associated with severe alveolar bone loss and internal root resorption. The patient was initially treated for ITP with dapsone. Surprisingly, dapsone, which is a bacteriostatic, anti-inflammatory, and immunomodulating agent, is a drug used in the treatment of LAD, ${ }^{1}$ however, this patient developed LAD after dapsone treatment. Although dapsone is frequently prescribed compared to other second-line treatments that can be an option for the less severe form of ITP, ${ }^{24}$ a severe allergic reaction erupted on her skin. Therefore, the physicians treated her with $60 \mathrm{mg} /$ day prednisolone and gradually reduced the prednisolone dosage when the skin showed hypopigmentation. From her medical history, following treatment of ITP with dapsone, the patient developed LAD. Although the etiology of drug-induced LAD remains unclear, it might be caused by an immune response from drug-derived hapten-protein antigens. However, because drug-

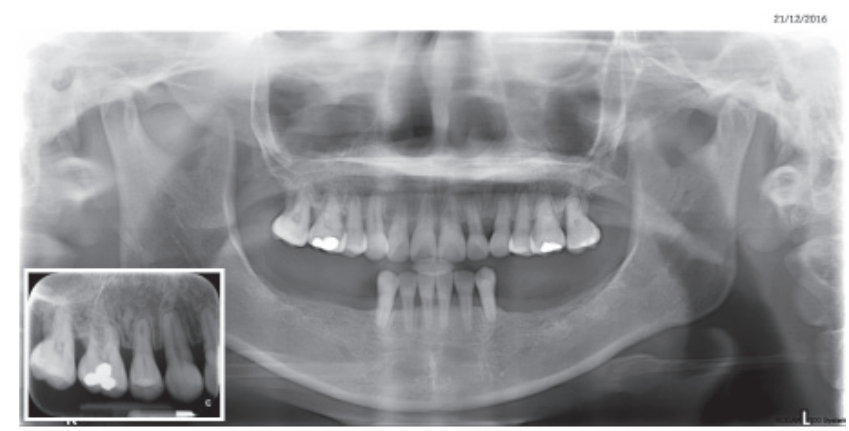

Fig. 6. Panoramic radiograph from December 2016 demonstrating that many teeth had been extracted, however, the internal root resorption on the maxillary right second premolar was still the same size induced LAD is more severe than spontaneous LAD, we cannot rule out that her LAD developed spontaneously. ${ }^{25}$

Since the first visit, this patient had developed many systemic diseases. EGPA was ultimately diagnosed by her physicians. EGPA, or Churg-Strauss syndrome (CSS), is characterized by disseminated necrotizing vasculitis with extravascular granulomas occurring in patients with asthma and tissue eosinophilia. ${ }^{26}$ EGPA is also a rare disease with an incidence in Europe of 0.5-6.8 new cases/year per million people; however, a case of EGPA in a Thai patient has never been reported. This disease most commonly affects subjects between 40-60 year-old, with a mean age at diagnosis of 48 years. ${ }^{19}$ Other manifestations of EGPA include major salivary gland involvement with the development of a focal mass or enlargement and neurolaryngeal involvement with dysphonia. ${ }^{27-30}$ Treatment of patients with EGPA must be performed by experienced physicians who are specialists in rare autoimmune diseases. A combination of high dose corticosteroids and cyclophosphamide remains the gold standard for the treatment of severe EGPA cases; however, the use of biological agents such as rituximab or mepolizumab seems to be a promising therapeutic alternative. ${ }^{20,26}$ Our patient's oral radiographic findings showed internal root resorption of the maxillary right second premolar and generalized severe alveolar bone loss between the first visit and the 2-year follow-up. An excessive loss of crestal bone height is almost never seenas a complication of orthodontic treatment and minimal effects on crestal bone level are observed during longterm follow up. ${ }^{31}$ The severe alveolar bone loss may be due to the disseminated necrotizing vasculitis that can occur in EGPA. Therefore, it is unreasonable to suspect that the periodontitis in this case occurred from orthodontic force 3 years after treatment was completed. Thus, based on the patient's history, clinical attachment loss and radiographic images, aggressive generalized periodontitis in the course of EGPA was the diagnosis in this case. However, this case was difficult to manage from a periodontal perspective. Conventional periodontal treatment was performed 
by a periodontist since 2014, however, there was no improvement due to her EGPA involvement. Moreover, the patient did not come for follow-up visits for 3 years, therefore, rapid periodontal progression was seen in almost all teeth. Periodontal treatment was ineffective in halting the progression of the patient's generalized alveolar bone loss. Multiple teeth were extracted because of mobility from severe bone loss. Many teeth showed apical root resorption that could have resulted from orthodontic force during fixed orthodontic treatment. A previous systematic review concluded that comprehensive orthodontic treatment increased the incidence and severity of root resorption, with heavy forces being particularly harmful. ${ }^{32}$ In our case, it might be possible that EPGA can cause severe bone loss. However, the size of the internal root resorption lesions was similar to that at her first visit.

\section{Conclusion}

This case report presents the very rare finding of both LAD and EGPA in the same patient. In addition, this is the first report of a case of LAD and EGPA associated with severe generalized alveolar bone loss and internal root resorption. Moreover, the progression of the generalized severe alveolar bone loss in this case could not be prevented.

\section{References}

1. Eguia del VA, Aguirre UJM, Martínez SA. Oral manifestations caused by the linear IgA disease. Med Oral, 2004;9:39-44.

2. Neville BW, Damm DD, Allen CM, Chi AC. Oral and maxillofacial pathology. $4^{\text {th }}$ edition, St. Louis: Saunders Elsevier; 2016:721.

3. Angiero F, Benedicenti S, Crippa R, Magistro S, Farronato D, Stefani M. A rare case of desquamative gingivitis due to linear IgA disease: morphological and immunofluorescence features. In Vivo, 2007; 21:1093-1098.

4. Godfrey K, Wojnarowska F, Leonard J. Linear IgA disease of adults: Association with lymphoproliferative malignancy and possible role of other triggering factors. Br J Dermatol. 1990;123:447-452.

5. Wakelin SH, Allen J, Zhou S, Wojnarowska F. Drug-induced linear IgA disease with antibodies to collagen VII. Br J Dermatol. 1998;138:310-314.

6. Gabrielsen TO, Staerfelt F, Thune PO. Drug induced linear IgA deposits along the basement membrane. Acta Derm Venereol. 1981;61:439-441.

7. Mc Whirter JD, Hashimoto K, Fayne S, Ito K. Linear IgA bullous dermatosis related to lithium. Arch Dermatol. 1987;123:1120-1122.

8. König C, Eickert A, Scharfetter-Kochanek K, Krieg T, Hunzelmann N. Linear bullous IgA dermatosis induced by atorvastin. J Am Acad Dermatol. 2001:44:689-692.

9. Plunkett RW, Chiarello SE, Beutner EH. Linear bullous dermatosis in one of two piroxicam induced eruptions: A distinct immunofluorescence trend revealed by the literature. J Am Acad Dermatol. 2001;45:691-696.

10. Avci O, Okmen M, Cetiner S. Acetaminophen induced linear IgA bullous dermatosis. J Am Acad Dematol. 2003;48:299-301.

11. Bachot N, Wechsler J, Demoule A, Roujeau JC. Amiodarone related linear IgA bullous dermatosis. J Am Acad Dermatol. 2003;49:e2.

12. Shimanovich I, Rose C, Sitaru C, Bröcker EB, Zillikens D. Localized linear IgA disease induced by ampicillin/sulbactam. J Am Acad Dermatol. 2004;51:95-98.

13. Rashid Dar N, Raza N. Drug induced linear IgA disease with unusual features: Koebner phenomenon, local insulin sensitivity and annular blister of the nipples. Acta Dermatovenerol Croat. 2008;16:215-217.
14. Panasiti V, Rossi M, Devirgiliis V, Curzio M, Bottoni U, Calvieri S. Amoxicillin-clavulanic acid-induced linear immunoglobulin $A$ bullous dermatosis: Case report and review of the literature. Int J Dermatol. 2009;48:1006-1010.

15. Kocyigit P, Akay BN, Karaosmanoglu N. Linear IgA bullous dermatosis induced by interferon-alpha 2a. Clin Exp Dermatol. 2009;34:e123-124.

16. Nantel-Battista M, Al Dhaybi RA, Hatami A, Marcoux D, DesRoches A, Kokta V. Childhood linear IgA bullous disease induced by trimethoprim-sulfamethoxazole. J Dermatol Case Rep. 2010;4:33-35.

17. Choudhry SZ, Kashat M, Lim HW. Vancomycin-induced linear IgA bullous dermatosis demonstrating the isomorphic phenomenon. Int J Dermatol. 2015;54:1211-1213.

18. Porter SR, Scully C, Midda M, Eveson JW. Adult linear immunoglobulin A disease manifesting as desquamative gingivitis. Oral Surg Oral Med Oral Pathol. 1990;70:450-453.

19. Gioffredi A, Maritati F, Oliva E, Buzio C. Eosinophilic granulomatosis with polyangiitis: An overview. Front Immunol. 2014;5:549.

20. Mouthon L, Dunogue B, Guillevin L. Diagnosis and classification of eosinophilic granulomatosis with polyangiitis (formerly named Churg-Strauss syndrome). J Autoimmun. 2014;48-49:99-103.

21. Alberici F, Martorana D, Bonatti F, Gioffredi A, Lyons PA, Vaglio A. Genetics of ANCA-Associated vasculitides: HLA and beyond. Clin Exp Rheumatol. 2014;32:90-97.

22. del Valle AE, Martínez-Sahuquillo A, Padrón JR, Urizar JM. Two cases of linear IgA disease with clinical manifestations limited to the gingiva. J Periodontol. 2003;74:879-882.

23. Joseph TI, Sathyan P, Goma Kumar KU. Linear IgA dermatosis adult variant with oral manifestation: A rare case report. J Oral Maxillofac Pathol. 2015;19:83-87.

24. Mahévas $M$, Michel $M$, Godeau B. How we manage immune thrombocytopenia in the elderly. Br J Haematol. 2016;173:844-856.

25. Chanal J, Ingen-Housz-Oro S, Ortonne N, Duong TA, Thomas ML. Linear IgA bullous dermatosis: Comparison between the druginduced and spontaneous forms. Br J Dermatol. 2013;169:1041-1048.

26. Greco A, Rizzo MI, De Virgilio A, Gallo A, Fusconi M, Ruoppolo G. Churg-Strauss syndrome. Autoimmun Rev. 2015;14:341-348.

27. Gambari PF, Ostuni PA, Lazzarin P, Fassina A, Todesco S. Eosinophilic granuloma and necrotizing vasculitis (Churg-Strauss syndrome?) involving a parotid gland, lymph nodes, liver and spleen. Scand J Rheumatol. 1989;18:171-175.

28. Boin F, Sciubba JJ, Stone JH. Churg-Strauss syndrome presenting with salivary gland enlargement and respiratory distress. Arthritis Rheum. 2006;55;167-170.

29. Tovoli F, Vannini A, Masi C, Balbi T, Bolondi L, Cavazza M. Eosinophilic granulomatosis with polyangiitis of the major salivary glands: A case of sialadenitis in a young patient. Intern Med. 2013;52:2131-2134.

30. Mazzantini M, Fattori B, Matteucci F, Gaeta P, Ursino F. Neuro-laryngeal involvement in Churg-Strauss syndrome. Eur Arch Otorhinolaryngol. 1998;255:302-306.

31. Proffit WR, Fields HW, Sarver DM, Ackerman JL. Contemporary orthodontics. $5^{\text {th }}$ edition, St. Louis: Elsevier Mosby; 2013:303.

32. Zahrowski J, Jeske A. Apical root resorption is associated with comprehensive orthodontic treatment but not clearly dependent on prior tooth characteristics or orthodontic techniques. J Am Dent Assoc. 2011;142:66-68. 